\title{
Zoning of town on undermined territory using GIS software
}

\author{
Pavel Zuev ${ }^{1 *}$, and Andrey V edernikov ${ }^{1}$ \\ ${ }^{1}$ The Institute of M ining of the U ral branch of the Russian A cademy of Sciences, 620075, \\ Ekaterinburg, Russia.
}

\begin{abstract}
: for settlements located near mines and quarries, it is often necessary to zoning areas that are affected by mining operations. M ost often, their influence is manifested in the form of subsidence of the earth @ surface, sometimes sinkholes. It is particularly relevant for the "factory-type" towns of the $U$ rals, where historically industrial settlements devel oped together and on the basis of mining and metallurgical industries, often having common borders. After decades, and sometimes centuries, the justified and safe use of these territories causes serious problems due to fragmentation and lack of information about their condition. A similar problem was encountered by the Berezovskiy town in the Middle Urals, most of whose territory was undermined. The closure and subsequent flooding of part of the mines of the previously city-forming gold mine led to the need to study its territory. To do this, a method was developed and zoning was performed in a step-bystep manner in the geoinformation system, and the consequences of flooding were established. In the process of implementation, all the engineeringgeological, geodetic and other information provided by the mine was used. The results are unique due to the uniqueness and heterogeneity of the parameters of underground workings, sinkholes on the earth @ surface caused by workings that are densely located on the studied territory.
\end{abstract}

\section{Introduction}

The completion of the deposits development leads to a lot of works and activities. One of the ways for eliminating the developed space is flooding of mines with water. If there are residential and industrial facilities on the surface, it is necessary to determine the degree of possible impact of underground workings on the state of the day surface for further exploitation of the mined areas. The Berezovskiy town of the Sverdlovsk region (Russia) is almost completely located within the limits of a deposit field developed since the beginning of the mining era in the M iddle U rals.

\section{Problem set}

This paper examines the assessment of the catastrophic consequences of flooding part of the B erezovskiy mine for the social and industrial infrastructure of the town. This mutual location of the town and the underground mining area is typical for the entire Middle Urals. The

\footnotetext{
* Corresponding author: zuev@ igduran.ru
} 
process of rock displacement comes to the fore as a source of catastrophic events. The builtup urban area retains relative stability most of the time. However, with significant flooding of the sub-devel oped area, stability decreases and there is a danger of further development of displacement processes. New collapse craters, sinkholes, cracks, and smooth deformations that exceed the maximum allowable values may occur. Due to the sudden nature of the deformation processes manifestations, they pose a danger to the population of the town and are associated with significant material damage [1,2].

The second most important source of catastrophic events can be called flooding of such areas [3], the absolute elevations of the territories which will be lower than the absolute elevations of the groundwater level, formed as a result of the elimination of the established depression funnel during the working mine drainage. The flooding factor will be manifested in the penetration of groundwater into basements, wetting and subsequently - the violation of the foundations, in some cases - flooding and waterlogging.

The third factor in the significance and probability of occurrence as a source of catastrophic events can be called seismogeodynamic processes, expressed in man-made earthquakes. Their occurrence comes from the large-scale influence of mining on the violation of the initial stress-strain state and the formation of a secondary technogenicchanged stress state. Accumulated elastic deformations caused by the concentration of stresses and deformations around the worked-out spaces, during the flooding of the massif, can manifest themsel ves as movements along with tectonic disturbances. The level of seismic impact on buildings and structures depends on the speed and magnitude of movement and most often does not cause serious damage. B ut buildings and structures located directly above the core can receive serious damages from the deformations $[4,5,6]$.

The manifestations of these three main sources of catastrophic events are complicated by two interrelated specific factors. First, the town is completely located on the territory of the deposit. Secondly, the deposit has been developed for 265 years with a full variety of mining technologies inherent in different periods of its existence: State-owned mining of gold for more than 150 years was conducted in the surface of the deposit at depths not exceeding 45$50 \mathrm{~m}$ [7]. During this period, more than 1000 small mines were built. In addition, artisanal excavation of gold ore was carried out everywhere. During WWI and then Civil War, all these mines were flooded.

Then, in the 20-30s of the last century, the mine was rebuilt, new mines were built with modern mining technologies, accompanied by the formation of craters on the earth $\odot$ surface, collapses, dips and the formation of displacement molds. Currently, the development of the deposit is carried out by two mines: "Yuzhnaya" ("Southern") and "Severnaya" ("Northern"), which conduct mining operations at depths of 314 meters and 512 meters, respectively.

Thus, the infrastructure of the Berezovskiy is closely intertwined with the areas of the negative impact of mining developments. In this regard, any changes in mining operations, especially such radical ones as flooding of mine workings and flooding of host rocks, require a serious study by specialized organizations.

\section{Site Geology}

Geologically, the ore field of the studied area is located within the Ural-Tobolsk anticlinorium in a lowered block limited by submeridional faults and large bodies of ancient gabbros and hyperbasites (from the south and north) [8], by Hercynian granitoids (from the west and east). The area of the ore field is about $60 \mathrm{~km}^{2}$. The block is composed of Lower Paleozoic stratified strata, containing sills and laccolithic bodies of serpentinized peridotites and pyroxenites. Rocks are breached by numerous dikes of plagioporfirs, granitporfirs, lamprophirs of various ages. The length of the dikes is up to $20 \mathrm{~km}$, the thickness is $2-40 \mathrm{~m}$, the strike is submeridional, the fall is steep. 
The veins within the ore field are unevenly distributed. Changes in rocks are widely developed - listvenitization of hyperbasites and sedimentary-volcanogenic rocks, berezitization of vein granitoids. Ore veins are composed of coarse-grained quartz, carbonate, and sulfides. The main ore minerals are pyrite, in some areas - hal enite, tetrahedrite, aikinite, chalcopyrite, native gold, and others. Gold (fineness $800-900$ ) is distributed unevenly in the form of fine dispersed inclusions and larger accumulations, sometimes in the form of small nuggets on the upper horizons. Clusters of veins in dikes and in the host rocks are worked out. The deposit is developed by underground mining mainly with ore shrinkage, less often with sub-floor blasting and horizontal layers excavation with a hydraulic filling of the mined space (at lower horizons) [8].

According to hydrogeological data, the main source of flooding of the deposit is fractured-vein water, associated with tectonic disturbances, dikes of granodiorites and quartz veins, which are natural underground drains and at the same time are conductors of surface water [3]. The low hypsometric position of the B erezovskiy deposit in a closed basin caused the creation of favorable conditions for the accumulation of underground water due to the infiltration of precipitation from the drained catchment area.

There are two vertical filtration zones:

upper - ground drainage zone;

lower - area of the local tectonic fracture systems.

In the upper zone, the permeability of reservoirs is determined by exogenous fracturing, tectonic fracturing, and technogenic fracturing, formed by the processes of rock displacement during mining.

At depths of more than $220 \mathrm{~m}$, the zone of local tectonic fractured systems begins. These systems are usually linear in nature, with complex geometries, various sizes, and filtration parameters. Sources of inflow here are areas of exit to the zone of a soil drain. The hydraulic connection between the individual fracture systems is usually absent or is realized through the zone of soil flow.

The basic values of water conductivity, in general, are relatively low. Water capacity varies from the first units to $50-100 \mathrm{~m}^{2} /$ day, water flows to wells in stationary mode do not exceed 1-3 liters/s.

Zones of discontinuous tectonic disturbances and contacts of intrusive bodies with strata of a different lithological and petrographic composition are characterized by increased water cut.

\section{Materials and Methods}

The research purpose is the development of a method for visualizing information about the nature and degree of undermining of the land, which makes it possible to reasonably decide on the involvement of the undermined areas in economic use. The research is carried out by geoinformatics methods, the use of which provides a reasonable approach to solving the task of the safe involvement of previously developed territories in the economic activity.

This work arose in connection with the consideration of the possibility of discontinuing funding for pumping water from the old mines. The Berezovskiy administration set a task to determine the consequences of filling the voids of the sub-developed territories with water based on existing geodesic and hydrogeological surveys. As part of the task, according to the available survey data, studies and analysis of the developed areas were carried out to structure the parameters and predict the geomechanical state of the studied massif.

At the mine, long-term monitoring of the city $\odot$ under-mined territories was conducted, and information about land subsidence was documented. There was also data on the size of the recorded underground workings - plans and projections of mines, maps with areas of mining. According to preliminary data, it was determined that the undermined territory occupies about $70 \%$ of the entire area of the town. Therefore, the creation of a geo- 
information package based on this information has become an important step for zoning these territories.

To create the package, we used the open geographic information system Quantum GIS (QGIS), distributed free of charge and compatible with most of the similar tools available on the market. Functionally, this system is fully consistent with the task $[10,11]$.

A s mentioned earlier, one of the sources of information was the logs of various violations and failures of the earth surface of the mined area, which have been logged at the mine since 1957. The failures were divided into two categories - by the time period and by the recorded diameter of the funnel. The map of the Berezovskiy town from the O penStreetM ap (OSM ) was taken as a basis. W ater objects, vegetation, residential and industrial infrastructure, land use zones, roads, and the hydro grid were laid out in separate layers.

\section{Results and discussion}

As a result of the log analysis, the parameters of the recorded deformations were determined and a table was compiled for the entire territory. It contains the following parameters: date of formation of the sinkhole, location reference, reference to the enclosing dike, size (diameter), depth, and geographical coordinates. A ttribute tables were created that provided visualization of statistically convenient layers. Based on tables for statistical representation, all manifestations of subsidence were divided into 5 ranges based on their size. Then layers were divided into 5 time periods. This is how the subsidence map was formed, which is shown in figure 1.

Including, during the development of the package, a layer of dikes was created within the field. Information on used dikes was received from the administration of the mine, it is based on the projection sections of these intrusive bodies. A statistical assessment of the mining of dikes was made using the QGIS. A s a result, two layers were formed - the spatial position of the dikes and the degree of their underworking. The degree of underworking was divided for four categories: $0-25 \%, 25-50 \%, 50-75 \%, 75-100 \%$ [6]. Having obtained the ratio of the number of sinkholes to the degree of working out of intrusive bodies plotted on one map, their relationship was established at the level of technogenic genesis.

M ost of the dips are expectedly lie near the most mined dikes, which determines their formation on the surface.

In the direction of further development of the geo-information package, a combined plan of the Berezovskiy town was obtained with the areas marked on it where mining operations were carried out. Thus, by combining the three main thematic layers (recorded deformations, the degree of underworking of dikes and well-known mine workings), a potentially dangerous area for the development of geomechanical processes of technogenic origin was figured out using an analytical method (Figure 2) [12,13]. 


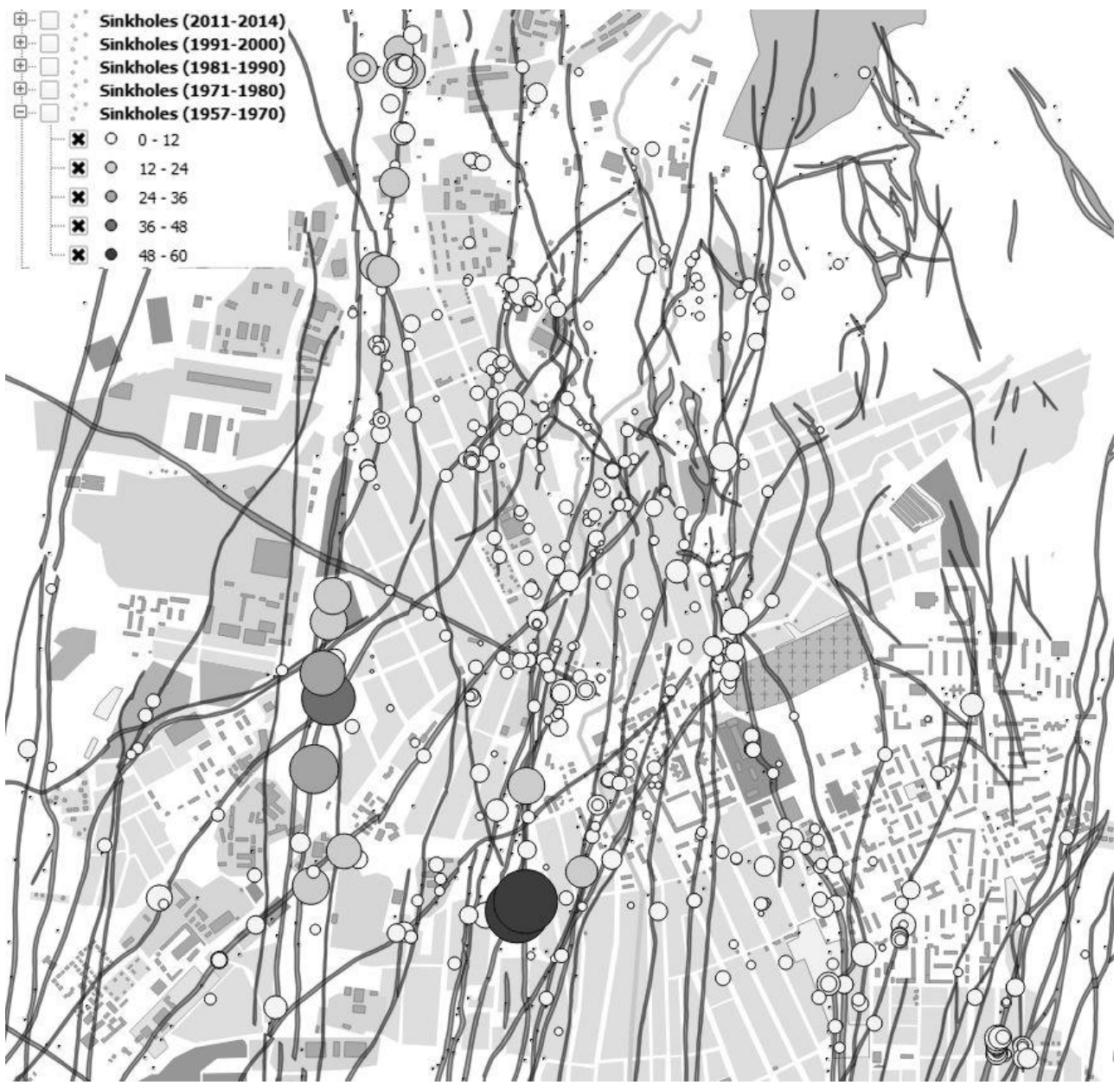

Fig.1. $M$ ap of sinkholes, in the upper-left corner there are 5 time ranges, which include 5 layers with sinkholes distributed along the diameter of the collapse funnel, dykes crossing the town are shown.

\section{Conclusions}

The study confirmed the possibility of predicted hazards when the mine is flooded. The occurrence of intensive processes of rock movement is inevitable due to the flooding of rocks susceptible to weathering [14]. B ased on the results of using the geo-information package in predicting rock movement, the city management decided to continue funding the pumping of water from empty mines space.

Observations of the integrity of the earth's surface in the researched area are ongoing. The project is developing, the stress-strain state is permanently changing, so adding new data contributes to a more detailed understanding of the rock movement processes and the formation of a more detailed picture of them, which is reflected in the regulatory documents. Completed for State Task 0405-2019-0007. 


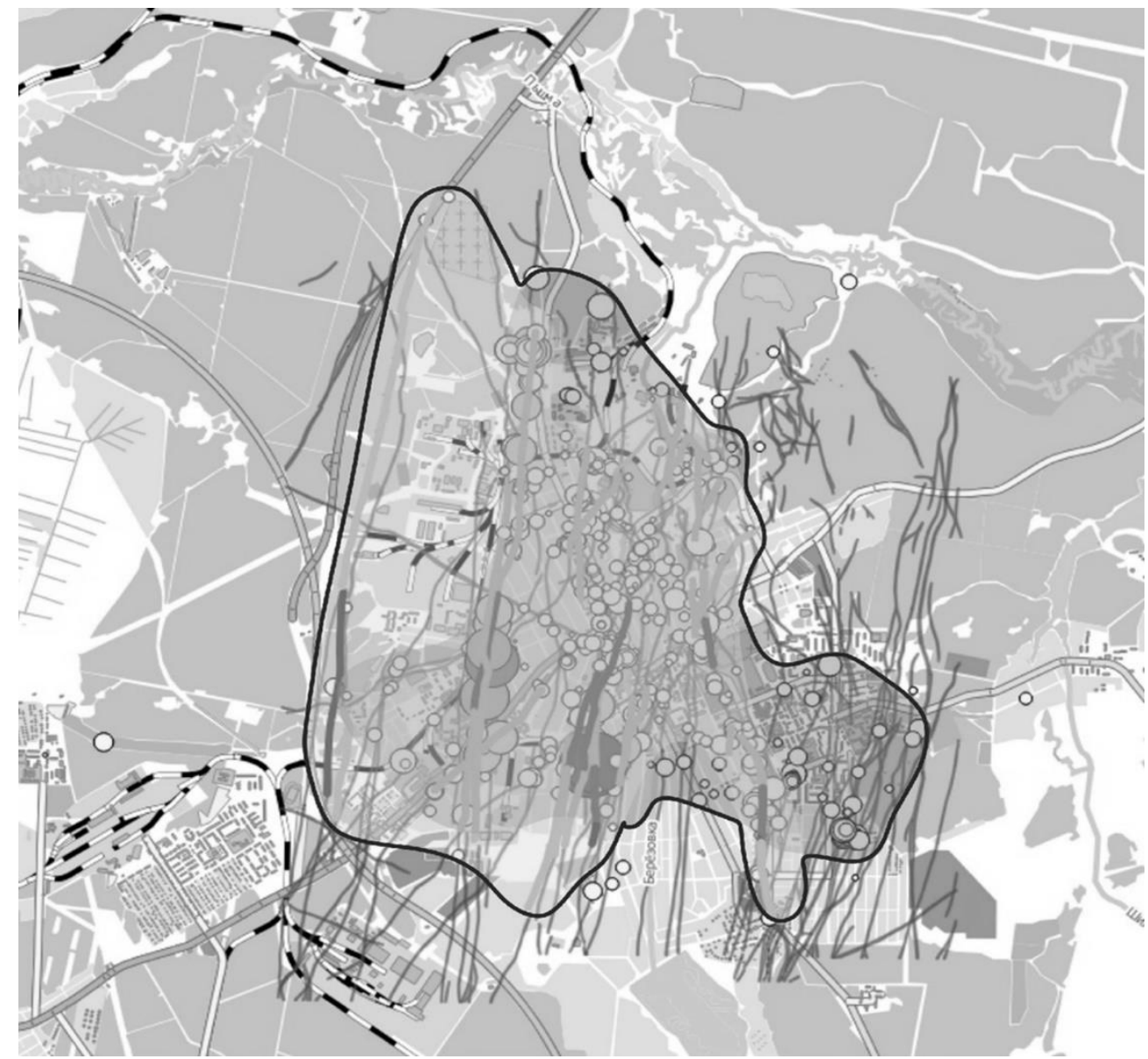

Fig. 2. A potentially dangerous area for the development of rock shifting processes is highlighted by a transparent area on the territory of the city.

\section{References}

1. J.E. Turney, Subsidence above inactive coal mines: information for the homeowner, Mining \& Safety and the Colorado Geological Survey, 36 (Denver, USA . 1985)

2. D.V. Grigoriev, A.S. V edernikov, Problemy nedropolzovaniya, 4, 137-143 (2019)

3. T. Sh. Dalatkazin, Y. P. K onovalova, Problemy nedropolzovaniya, 3, 60-66 (2017)

4. A. D. Sashourin, Gornyi zhurnal, 1, 29-32 (2017)

5. A. D. Sashourin, Problemy nedropolzovaniya, 1, 38-44 (2015)

6. D.V. Grigoriev, Results of the study of the rock mass in the construction area of the Y ekaterinburg metro, Materials of the XII Ural youth scientific school of Geophysics, 5962 (Perm: Mining Institute UB RAS, 2011)

7. D. A. Kleymenov, V. G. Albrecht, Y. V. Erokhin, A. S. B atalin, A. A. Batalina B erezovsky gold deposit. History and minerals, 200 (Ekaterinburg: "Uralskiy rabochiy", 2005)

8. N. I. Borodaevskiy, M. B. Borodaevskaya, Berezovsky ore field, 261 (Moscow: Gosgeol techizdat, 1947)

9. A. A. Panzhin, P. I. Zuev, Tasks of development of mining and geological information systems for accounting of interaction of subsurface use objects with the natural environment. Forum «Days of Earth science at Urals», 92-94 (Ekaterinburg, 2012) 
10. V.Y. Tsvetkov, Information models and geoinformation models Educational resources and technologies, 4 (16), 114-120 (2016) DOI: 10.21777/2312-5500-2016-4-114-120

11.Jixiong Zhang, Qiang Zhang, Qiang Sun, Rui Gao, Deon Germain, Sami Abro, Environmental Earth Sciences, 74 (2), 1439 (2015)

12. J angw on Suh, Y osoon Choi, Hyeong-D ong Park, Environmental E arth Sciences, 75 (10) $1,(2016)$

13. M uhammad Ahsan Mahboob, Bekir Genc, Turgay Celik, Sarfraz Ali, Iqra Atif, GeoJ ournal, 1 (2019)

14. Radosław Murdzek, H ubert M alik, Andrzej Leśniak, E $3 S$ W eb of Conf., 36, 02006 (2018) doi: 10.1051/e3sconf/20183602006 